\title{
Why are marine ecosystems biologically more diversified than their equivalent terrestrial ecosystems?
}

\section{Short communication}

Marine ecosystems are ecosystems found in a body of water. They are composed of the communities of organisms that are dependent on each other and on their environment live in marine ecosystems. Marine waters cover two-thirds of the surface of the earth. ${ }^{1}$ Such places are considered ecosystems because the plant life supports the animal life and vice-versa. Marine ecosystems are very important for the overall health of both marine and terrestrial environments. According to the World Resource Center, coastal habitats alone account for approximately $1 / 3$ of all marine biological productivity, and estuarine ecosystems (i.e. salt marshes, sea-grasses, and mangrove forests) are among the most productive regions on the planet. In addition, other marine ecosystems, such as coral reefs provide food and shelter to the highest levels of marine diversity in the world. Marine ecosystems usually have a large biodiversity and are, therefore, thought to have a good resistance against invasive species. However, exceptions have been observed, and the mechanisms responsible in determining the success of an invasion are not yet clear. ${ }^{1}$

On the other hand, terrestrial ecosystems are ecosystems that are found only on landforms. They mainly support a community of organisms and their environment that occurs on the land masses of continents and islands. The base of the food web in the terrestrial ecosystems is occupied by green plants, which are the only organisms capable of utilizing the energy that comes from the sun and inorganic nutrients obtained from the soil to produce organic molecules. ${ }^{1}$ Even though the tropical rain forest ecosystem is biologically more diversified, the other terrestrial ecosystems, such as tundra (i.e. arctic), taiga (i.e. boreal forests), temperate deciduous forests, Mediterranean shrub-land, mountains, temperate grasslands, tropical savannah, and desert ecosystems are biologically less diversified than their equivalent marine ecosystems. ${ }^{1-5}$

There are a number of plausible hypotheses that explain why the marine ecosystems are biologically more diversified than their equivalent terrestrial ecosystems. Some of them may include the followings.

\section{The productivity hypothesis}

Most of the time, nutrients are washed and deposited from the adjacent terrestrial ecosystems to the marines by various agents including moving water, wind, melting ice, landslides, and gravity so that most essential nutrients are readily available in the marine ecosystems where producers are able to prepare their food through the process known as photosynthesis. ${ }^{1,5}$ As water has high specific heat capacity, temperature fluctuations in the marine ecosystems are much lower (i.e. both diurnal and seasonal basis) than occur in terrestrial ecosystems of similar climates. This suggests that temperature fluctuations could have much negative effect to reduce survival, reproduction, population persistence, and biological diversity of organisms found in the terrestrial ecosystems especially in areas where water is a limiting factor. ${ }^{1}$ However, some nutrients can be drained
Special Issue - 2018

Solomon Ayele Tadesse

Department of Natural Resources Management, Debre Berhan University, Ethiopia

Correspondence: Solomon Ayele Tadesse, Department of Natural Resources Management, College of Agriculture and Natural Resource Sciences, Debre Berhan University, PO Box 445, Debre Berhan, Ethiopia, Tel +25I I I 6815440 (office), +25194670 3660 (mobile), Fax +25।I II68 I2065, Email solomon.ayele1972@gmail.com

Received: July 14, 2018 | Published: July 31, 2018

out of the marines to the terrestrial ecosystems by fish eating birds and deposited as guano in the terrestrial ecosystems. In addition to disturbing marine organisms, over exploitation of natural resources by humans, such as hunting animals, cutting plants, over fishing, waste disposal, thermal heating, navigation, pollution, and water mining can reduce the availability of nutrients in the marine ecosystems. Moreover, as compared to the terrestrial ecosystems, when the depth of the water increases, light (i.e. because the atmosphere is more transparent than water) will be a limiting factor to reduce biological productivity and diversity in the marine ecosystems. Gases are also more available in terrestrial ecosystems than in marine ecosystems. Those gases include carbon dioxide that serves as a substrate for photosynthesis, oxygen that serves as a substrate in aerobic respiration, and nitrogen that serves as a substrate for nitrogen fixation. ${ }^{1,4,5}$ These may also have negative effects to reduce productivity and biological diversity in the marine ecosystems.

\section{The water availability hypothesis}

Water is one of the most abundant resources in the marine ecosystems. Moreover, water constitutes about 50 to 97 percent of the weight of all plant and animal life and about 70 percent of the human body. Therefore, water is essential to all living organisms for various purposes including serving as a raw material for photosynthesis by which green plants prepare their own food, grow and make chemical energy available for other heterotrophic organisms, dissolves and transports nutrients from the soil into and through plants, reduces $\mathrm{CO}_{2}$ in photosynthesis, determines world climate and weather which in turn determines the structure and function of natural ecosystems, unites the various components of the ecosphere (i.e. hydrosphere, lithosphere, and biosphere) into a whole, facilitates digestion and metabolism, reduces body temperature through evaporative cooling, and facilitates the removal of metabolic wastes. In addition, most organisms can survive for weeks without food but only days without water. Growth, size, reproduction, and general body condition of organisms usually benefit from optimum water supplies. Moreover, marine organisms are 
seldom exposed to desiccation while terrestrial organisms are often exposed to desiccation which in turn reduces biological diversity in the terrestrial ecosystems. Therefore, terrestrial ecosystems are distinguished from marine ecosystems by the lower availability of water and the consequent importance of water as a limiting factor. ${ }^{1,5}$

\section{The predation risk hypothesis}

Organisms living in the terrestrial ecosystems are influenced far more by gravity, while water supports marine organisms. Locomotion for terrestrial organisms requires much more energy than do marine organisms just to escape from risks of predation. Therefore, as compared to those organisms that live in the terrestrial ecosystems, I argue that organisms that live in marine ecosystems are relatively safe from the negative impacts of risks of predation.

\section{The competition hypothesis}

Diversity influences productivity by:

I. Ensuring the efficient use of resources. Different species use an ecosystem's resources in different ways. Having many species (i.e. high biodiversity) usually means that resources are used efficiently with little waste.

II. Complimentary interactions between species. Some species are thought to interact and use resources in ways that increase productivity for each other (e.g. mutualism). As compared to the terrestrial ecosystems, the efficient use of the resources help them cycle through the marine ecosystems faster and making them available for reuse by other organisms and ultimately reduce competition for limited resources in the marine ecosystems. This is why marine food chains often have a larger number of trophic levels and also much more stable than do terrestrial food chains. ${ }^{1-5}$

\section{The human factor hypothesis}

As compared to the terrestrial ecosystems, anthropogenic disturbances, such as settlement, urbanization, over grazing, fire, deforestation, human-wildlife conflicts, agricultural land expansions, collision, pollution, illegal hunting, and the likes are less common in the marine ecosystems. This is because the water body by itself will act as barrier for such kind of human activities in the marine ecosystems. As a result, I propose that marine ecosystems have greater probability to support more biodiversity as compared to their equivalent terrestrial ecosystems.

\section{Conclusion}

Marine ecosystems are found in a body of water whereas terrestrial ecosystems are ecosystems that are found only on landforms. Generally, the marine ecosystems are biologically more diversified than their equivalent terrestrial ecosystems. This is explained by various plausible hypotheses including the productivity hypothesis, the water availability hypothesis, the predation risk hypothesis, the competition hypothesis, and the human factor hypothesis. Therefore, it is recommended that future research can test the aforementioned plausible hypotheses either separately or in an integrated fashion via experimental and/or observational studies.

\section{Acknowledgements}

None.

\section{Conflict of interest}

Author declares that there is no conflict of interest.

\section{References}

1. Polis GA. Why are parts of the world green? Multiple factors control productivity and distribution of biomass. Oikos. 1999;86(1):3-15.

2. Oksanen L. Reindeer lichen (Cladina) vegetation of rock outcrops on a coast-inland transect in South Finland. Annales Botanici Fennici. 1981;18:133-154.

3. Oksanen L. Predation, herbivory, and plant strategies along gradients of primary productivity. In: Tilman D, Grace J, editors. Perspectives on plant competition. USA: Academic Press, New York; 1990. p. 445-474.

4. Ayal Y. Productivity, organism size, and the trophic structure of the major terrestrial biomes. Theor Ecol. 2010;4(1):1-11.

5. Oksanen L, Fretwell S, Arruda J, et al. Exploitation ecosystems in gradients of primary productivity. American Naturalist. 1981;118:240-261. 